\title{
Diferentes relações cálcio:fósforo disponíveis e fitase em dietas de poedeiras UFSM-V: desempenho produtivo, qualidade dos ovos e tecido ósseo
}

\author{
Different calcium relations: available phosphorus and phytase in diets of UFSM-V laying hens: \\ productive performance, egg quality and bone tissue
}

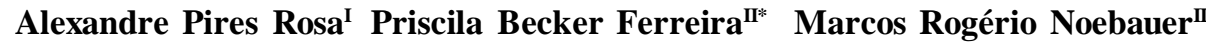 \\ Everton Luis Krabbe ${ }^{\mathrm{III}}$ Lucas Pedroso Colvero $^{\mathrm{IV}}$
}

\begin{abstract}
RESUMO
$O$ estudo teve como objetivo determinar os efeitos das diferentes relações cálcio:fósforo disponíveis $(\mathrm{Ca}: P d)$ e fitase em dietas à base de milho e farelo de soja sobre a qualidade dos ovos e o desempenho produtivo de poedeiras de ovos marrons. Foram utilizadas 144 poedeiras UFSM-V de 28 a 36 semanas de idade. $O$ delineamento experimental foi o inteiramente casualizado, com os tratamentos distribuídos em esquema fatorial $3 \times 2$, em que foram testadas três diferentes relações Ca:Pd $(8: 1 ; 11: 1 ; 14: 1)$ e dois níveis de fitase $\left(0\right.$ e 300FTU $\mathrm{kg}^{-1}$ de dieta), com seis repetições de quatro aves cada. Os parâmetros avaliados foram: peso corporal, consumo de dieta, conversão alimentar por massa de ovos, produção de ovos, altura de albúmen, massa de ovos, gravidade específica dos ovos, unidade Haugh e percentagem de cálcio e fósforo na tíbia. Os indices produtivos não foram afetados pelas relações Ca:Pd e nem pela utilização da enzima, sendo que o peso corporal das aves variou entre $1,927 \mathrm{~kg}$ e $2,118 \mathrm{~kg}$, e o consumo de ração foi em média de $120 \mathrm{~g}$ de ração ave-1 dia $^{-1}$. A qualidade interna dos ovos também não apresentou diferenças significativas, a altura de albúmen média foi de 8,78mm e a unidade Haugt de 94,66 em média. Dietas com relação Ca:Pd de 8:1 apresentaram interação com a enzima, melhorando o nível de Ca das tíbias das aves (Ca na tíbia=20,63\%). Com relação Ca:Pd igual ou superior a 11:1, não houve interação com a fitase, porém as aves apresentam percentagem de Ca superior na tíbia (Ca na tíbia $\pm 22 \%$ ).
\end{abstract}

Palavras-chave: enzima, gravidade específica, ovos de casca marrom, tíbia.

\section{ABSTRACT}

The study aimed to determine the effects of different calcium relations: phosphorus (Ca:Pd) and phytase in diets based on corn and soybean meal on egg quality and production on the performance of brown egg layers. It was used 144 $U F S M$-V layers, aging from $28^{\text {th }}$ to $36^{\text {th }}$ weeks. The experiment was a completely randomized design with treatments arranged in a $3 \times 2$ factorial arrangement, and three different Ca relations were tested: $P d(8: 1,11: 1,14: 1)$ and two phytase levels $(0$ and $300 F T U \mathrm{~kg}^{-1}$ diet) with six replicates of four layers each. The parameters evaluated were: body weight, feed intake, feed conversion by egg mass, egg production, albumen height, egg mass, egg specific gravity, Haugh units and percentage of calcium and phosphorus in the tibia. The production indices were not affected by the Ca:Pd relation or by the use of the enzyme, and the weight of the birds ranged from $1.927 \mathrm{~kg}$ and $2.118 \mathrm{~kg}$, and feed intake averaged $120 \mathrm{~g}$ of feed bird ${ }^{-1}$ day $^{-1}$. Internal egg quality also showed no significant differences, the average albumen height was $8.78 \mathrm{~mm}$ and the unit Haugt average was of 94.66. Diets with Ca:Pd of 8:1 showed interaction with the enzyme, improving the level of $\mathrm{Ca}$ in the Hens' tibia (Ca in tibia=20.63\%), with a Ca: Pd greater than or equal to 11:1. There was no interaction with phytase, but there was higher percentage of $\mathrm{Ca}$ in the tibia (Ca in tibia $\pm 22 \%$ ).

Key words: brown egg, enzyme, specific gravity, tibia.

\section{INTRODUÇÃO}

$\mathrm{O}$ aporte adequado de minerais para poedeiras comerciais é indispensável para a melhoria da qualidade interna e externa dos ovos, entre os minerais de maior importância pode-se citar o cálcio e o fósforo. O cálcio destaca-se pela importância para o crescimento e manutenção do tecido ósseo, além do

IDepartamento de Zootecnia, Universidade Federal de Santa Maria (UFSM), Santa Maria, RS, Brasil.

"Programa de Pós-graduação em Zootecnia, Departamento de Zootecnia, UFSM, Campus Universitário, 97105-900, Santa Maria, RS, Brasil. E-mail: pri_zoot@hotmail.com. *Autor para correspondência.

"I'Basf, The Chemical Company, Departamento de Química fina, São Paulo, SP, Brasil.

${ }^{\text {Iv }}$ Curso de Medicina Veterinária, UFSM, Santa Maria, RS, Brasil. 
equilíbrio eletrolítico, contração muscular e formação da casca do ovo. O fósforo é um importante constituinte da molécula de energia e está intrinsecamente relacionado com o cálcio.

O fósforo é considerado o terceiro ingrediente mais oneroso da alimentação animal, ainda podendo causar efeitos adversos no desempenho de poedeiras comerciais, se fornecido a menos ou a mais na dieta. O fósforo pode apresentar-se na forma de fitato, molécula naturalmente presente nos cereais e constitui a maior parte do fósforo total. O fitato como fator antinutricional para os não-ruminantes limita a absorção do fósforo e de cátions multivalentes, repercutindo em maiores custos de produção além de impacto negativo sobre o meio ambiente (BORGES, 1997).

Segundo os estudos realizados por RAVINDRAN et al. (1995), evidências indicam que a disponibilidade do fósforo fítico utilizado para aves varia de 0 a $50 \%$, dependendo da idade, tipo de ingrediente e diferentes níveis de fósforo, cálcio e vitamina $\mathrm{D}$. De forma geral, considera-se que somente $30 \%$ do fósforo total seria biodisponível para monogástricos (ROSTAGNO et al., 2000).

Para ROLAND \& GORDON (1996), poedeiras alimentadas com baixos níveis de cálcio hidrolisam melhor o fitato do que aves consumindo dietas com altos teores desse mineral. Além disso, esses autores sugerem que níveis altos de cálcio podem interferir no efeito da fitase, diminuindo a solubilidade do fitato. Níveis de cálcio acima de 0,70\% em pH 6,0 permitem a reação do cálcio e ácido fítico, formando o fitato de cálcio, que é um complexo inacessível à fitase pela competição do cálcio aos sítios ativos da enzima (McKNIGHT, 1997).

Segundo LÜDKE et al. (2002), o fósforo fítico, por ser de baixa disponibilidade para nãoruminantes, juntamente com fósforo inorgânico adicionado às dietas, resultam em altos níveis de minerais excretados nas fezes dos animais. Isso desencadeia alto índice de poluição ambiental em áreas de alta densidade de aves, devido à grande quantidade não apenas de fósforo, mas também de nitrogênio e cálcio excretados.

A suplementação com as enzimas exógenas fitases, alternativa para melhorar o aproveitamento do fósforo fítico, promove economia das fontes inorgânicas de fósforo, aspecto relevante quando se considera que estas fontes não são renováveis na natureza; e, se não ocorrerem mudanças em relação a sua exploração, projeta-se que estarão esgotadas em menos de 100 anos (BORGES, 1997).

Uma forma de reduzir os níveis de fósforo da dieta é a utilização de fitase exógena. ROSTAGNO et al. (2000), estudando níveis de fósforo disponível e fitase, 0 e 300FTU $\mathrm{kg}^{-1}$, afirmam que o nível ótimo de fósforo disponível foi de $0,375 \%$ na ração para o melhor desempenho de poedeiras semi-pesadas em produção.

Objetivou-se avaliar o efeito de diferentes relações Ca:Pd e fitase exógena em dietas de poedeiras de ovos marrons, sobre o desempenho zootécnico, qualidade dos ovos e matéria mineral das tíbias, utilizando dietas à base de milho e farelo de soja.

\section{MATERIAL E MÉTODOS}

O experimento foi realizado no Laboratório de Avicultura (LAVIC) do Departamento de Zootecnia da Universidade Federal de Santa Maria, no período de 11 de junho a 06 de agosto de 2004. As aves foram alojadas em galpão experimental de $60 \mathrm{~m}^{2}$, dotado de gaiolas de arame galvanizado, sendo que cada ave permaneceu em uma divisão de dimensão $0,25 \times 0,45 \times 0,40 \mathrm{~m}$, com comedouro frontal tipo calha e um bebedouro automático tipo taça. Foram utilizadas 144 poedeiras da linhagem $U F S M-V$ com 28 semanas de idade, resultantes do cruzamento de machos da raça Red Rhodes Island com fêmeas White Plymouth Rock.

O critério de seleção das aves para o experimento foi o peso corporal, baseando-se na uniformidade entre as unidades experimentais. Cada unidade experimental foi composta de uma gaiola de quatro divisões, com uma ave em cada divisão. As aves foram submetidas ao programa de iluminação crescente até $17 \mathrm{~h} \mathrm{luz} \mathrm{lia}^{-1}$. As dietas seguiram as recomendações de ROSTAGNO et al. (2000) para atender as exigências nutricionais das aves, que foram isonutritivas, exceto para nível de cálcio e fitase, conforme tabela 1.

Foi utilizado delineamento inteiramente casualizado, com os tratamentos distribuídos em um esquema fatorial $3 \times 2$, sendo três relações cálcio:fósforo disponível (8:1; 11:1 e 14:1) e dois níveis de fitase (0 e $300 F_{T U ~ ~ k g^{-1}}$ de dieta), distribuídos em seis tratamentos com seis repetições de quatro aves cada. Os dados foram submetidos à análise de variância e as médias comparadas pelo teste de Tukey a 5\% de significância. As análises estatísticas foram realizadas pelo programa estatístico SAS ${ }^{\circledR}$ versão 6.12 (STATISTICALANALYSIS SYSTEM, 1996).

Os parâmetros mensurados durante o período experimental compreendido entre a $28^{\mathrm{a}}$ e a $36^{\mathrm{a}}$ semana de idade foram peso corporal, produção de ovos, peso dos ovos, consumo de ração, conversão alimentar por massa de ovos, gravidade específica em soluções salinas, altura de albúmen, unidade Haugh e percentual de cálcio, fósforo e matéria mineral das tíbias. Para a determinação da produção, foram realizadas 
Tabela 1 - Composição centesimal e perfil nutricional dos diferentes tratamentos.

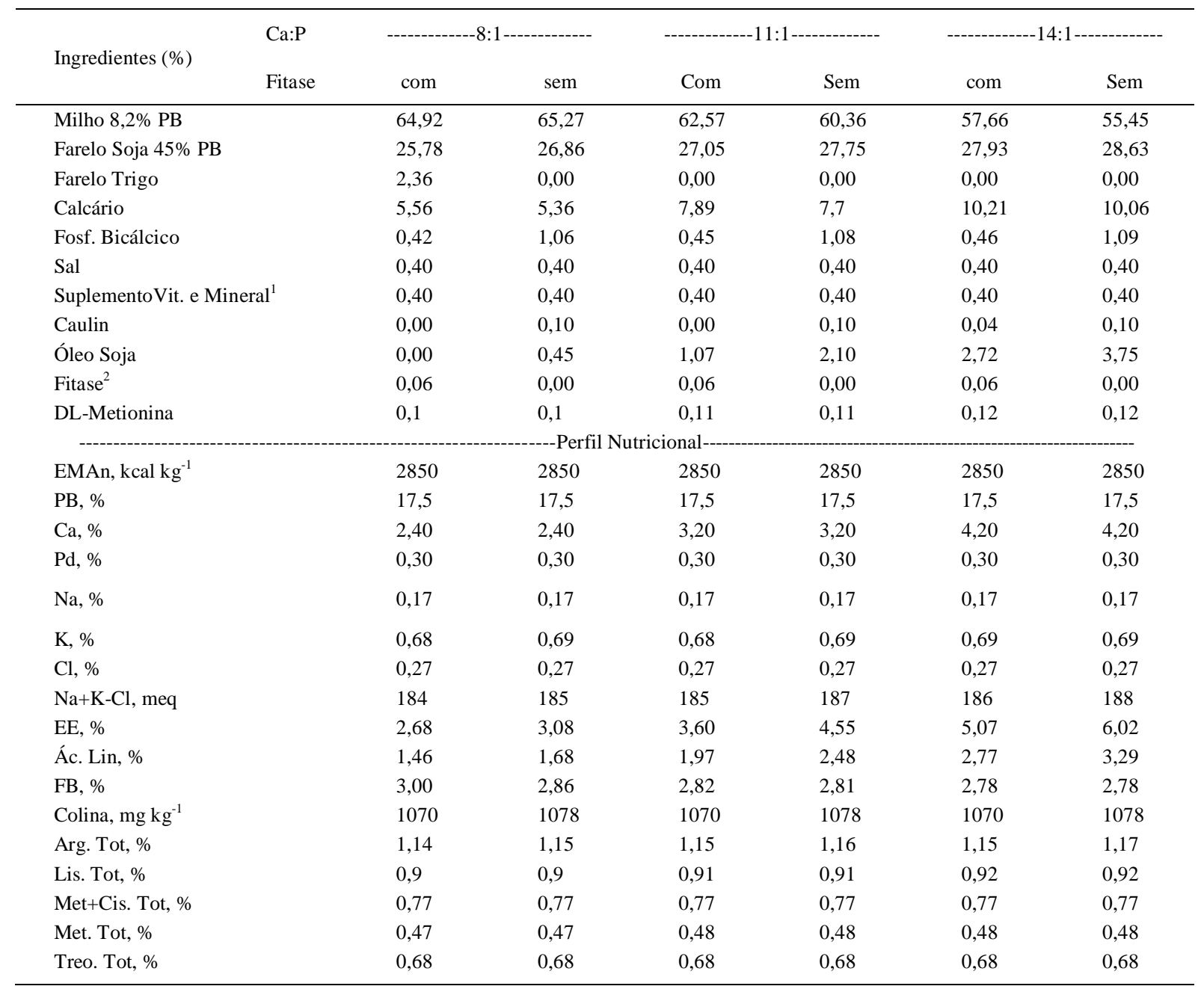

1 - Suplemento vitamínico e mineral: Níveis de garantia por quilograma de premix: Vit.A 2.750.000UI; Vit E 6.000mg; Vit D3 150.000UI; Vit K3 500mg; Ácido Nicotínico 8.000mg; Vit B1 550mg; Vit B12 3.750mg; Vit B2 1.875mg; Vit B6 1000mg; Ac Fólico 250mg; Biotina 45mg; Colina 66.000mg; Ác. Pantotênico 3.750mg; Metionina $89.100 \mathrm{mg}$; Cobre 2.400mg; Ferro 12.000mg; Iodo 120mg; Manganês $14.000 \mathrm{mg}$; Selênio $48 \mathrm{mg}$ e Zinco $13.000 \mathrm{mg}$.

2- Fitase comercialmente denominada NATUPHOS $5000 \mathrm{G}^{\circledR}$, pela qual se preconiza a atividade mínima em $5000 \mathrm{FTU}$.

quatro coletas diárias dos ovos e, para a avaliação dos parâmetros peso corporal, consumo e peso dos ovos, foram realizadas pesagens semanais. A qualidade dos ovos foi avaliada semanalmente através da gravidade específica, altura de albúmen e unidade Haugh. A gravidade específica dos ovos foi avaliada em soluções salinas, com densidades aferidas por densímetro analógico, entre 1,075 e 1,095, apresentando intervalos de 0,005 .

Para as avaliações de matéria mineral, cálcio e fósforo das tíbias, foram abatidas, ao final do experimento, duas aves por repetição. Após o abate, procedeu-se à dessecação da tíbia, sendo retirada a fíbula, porém mantidas a cartilagem tibiotársica, côndilo lateral e a cartilagem da tíbia ossificada, conforme metodologia descrita por LUCAS \& STETTENHEIM (1972). Posteriormente, as tíbias foram secas em estufa a $105^{\circ} \mathrm{C}$ por 24 horas. $\mathrm{O}$ teor de cinzas foi obtido por queima da matéria orgânica em mufla a $600^{\circ} \mathrm{C}$, durante 6 horas. Essas análises foram realizadas no Laboratório de Nutrição Animal do Departamento de Zootecnia da Universidade Federal de Santa Maria (UFSM).

Para determinação de fósforo, usou-se metodologia descrita por MALAVOLTA et al. (1989), para o cálcio, a técnica do permanganato e, para cinzas, procedeu-se à metodologia preconizada por SILVA (1981). Nas leituras de fósforo, foi usado espectrofotômetro e, para o cálcio, seguiu-se método 
de absorção atômica, sendo que ambas foram leituras realizadas no Laboratório de Solos da UFSM.

\section{RESULTADOS E DISCUSSÃO}

O peso corporal das aves durante o período experimental variou em média entre $1,927 \mathrm{~kg}$ e $2,118 \mathrm{~kg}$, sendo que este parâmetro não foi influenciado pelas relações cálcio:fósforo (8:1; 11:1 e 14:1), pelos níveis de fitase e nem pelas interações. Esses dados concordam com os obtidos por GORDON \& ROLAND (1998), que trabalharam com poedeiras de ovos marrons, a partir das 58 semanas de idade, com diferentes relações $\mathrm{Ca}: \operatorname{Pd}(8,3: 1 ; 9,3: 1$ 10,3:1; 25:1; 28:1 e 31:1) e verificaram não haver efeito das diferentes relações sobre esse parâmetro. Os resultados encontrados neste estudo evidenciam que mesmo a relação Ca:Pd de 8:1 sem adição de fitase foi suficiente para atender as exigências nutricionais das aves, durante o período avaliado, sem comprometer o seu peso corporal.

O consumo de ração das aves submetidas aos diferentes tratamentos não evidenciou diferença significativa, sendo esses resultados idênticos aos encontrados por BORRMANN (2001). Contudo, o autor observou que, com baixo nível de Pd $(0,1 \%)$, houve influência das relações Ca:Pd com fitase, elevando o consumo de ração. Durante este experimento o consumo de ração ave $\mathrm{dia}^{-1}$ foi em média $120 \mathrm{~g}$.
A taxa de postura das aves, conforme tabela 2, não foi influenciada pelas diferentes relações de Ca:Pd, fitase e pelas interações (Ca:Pd x fitase) em nenhum dos períodos estudados, concordando com TANGENDJAJA et al. (2002), que trabalharam com poedeiras de ovos marrons com 25 semanas de idade, suplementadas ou não com $300 \mathrm{FTU} \mathrm{kg}{ }^{-1}$ de dieta e dietas com $22 \%$ de farelo de arroz, não observando efeito significativo sobre a produção de ovos. Resultados semelhantes foram observados por LIM et al. (2003) e COSTA et al. (2004).

A conversão alimentar por massa de ovos não foi influenciada pelas relações Ca:Pd estudadas, fitase ou interação entre elas, divergindo com os resultados encontrados por SILVA et al. (2008), que, em poedeiras a partir da $28^{\mathrm{a}}$ semana de idade, obtiveram melhor conversão por massa de ovos com a relação Ca:Pd de 14:1 (4,2\% Ca e 0,3\% Pd) e a pior conversão com relação Ca:Pd de 11,6:1 (3,5\% Ca e 0,3\% Pd). Também observaram efeito significativo para interação, em que a relações Ca:Pd de 11,6:1 com 600FTU kg-1 de dieta melhorou a conversão por massa de ovos. A diferença entre os resultados encontrados por esses autores e os observados neste estudo é atribuída às diferentes quantidades de fitase utilizada.

Com base nos dados obtidos, nenhum parâmetro produtivo foi influenciado pelas relações cálcio:fósforo disponível. Esses resultados podem ser

Tabela 2 - Efeito das diferentes relações cálcio:fósforo, fitase e interação (Ca:Pd x fitase) sobre a taxa de postura (\%) das poedeiras $U F S M$-V.

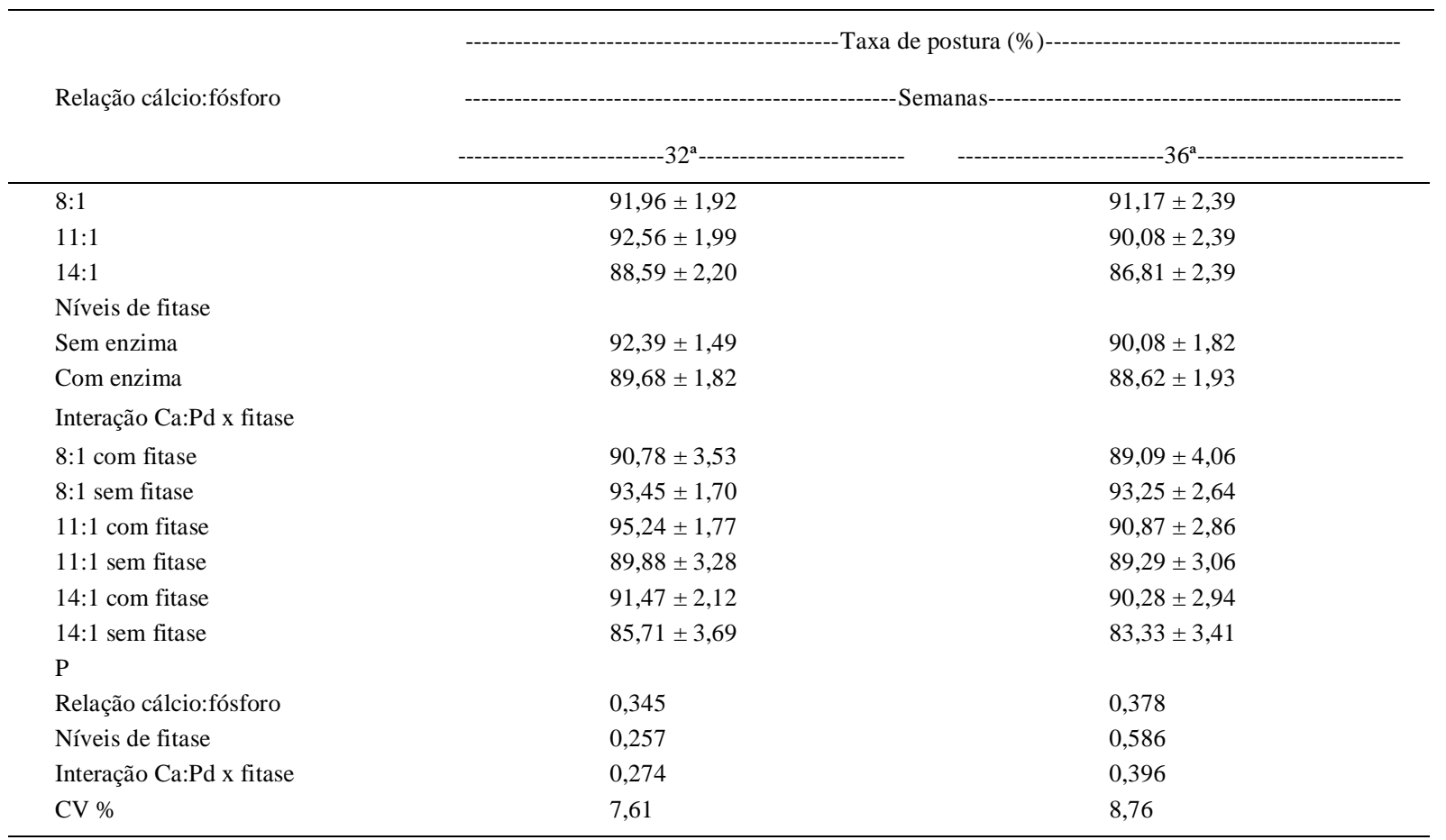

Ciência Rural, v.41, n.10, out, 2011. 
atribuídos à possibilidade de uma menor necessidade de cálcio para as aves em estudo, associada à maior disponibilidade do cálcio quando as relações $\mathrm{Ca}: \mathrm{Pd}$ foram reduzidas. Possivelmente, ainda esteja associada à maior mobilização de cálcio ósseo quando necessário. Esses resultados concordam com VIANA et al. (2009) que, alimentando poedeiras da linhagem Bovans Goldline, de 24 a 36 semanas de idade com as dietas: controle positivo, controle negativo com $0,15 \%$ de $\mathrm{P}$ disponível e controle negativo com adição de 200, 400 e $600 \mathrm{FTU} \mathrm{kg}^{-1}$ de dieta, não verificaram alterações no desempenho médio das aves, avaliado pelo consumo de ração, pela produção de ovos e pelo peso dos ovos, da mesma forma.

O peso dos ovos não foi influenciado significativamente pelas relações $\mathrm{Ca}: \mathrm{Pd}$ estudadas, níveis de fitase ou interação em nenhuma das semanas avaliadas, sendo que o peso dos ovos durante o período experimental variou entre 53,32g e 59,27g. Esses resultados concordam com GORDON \& ROLAND (1998), que não obtiveram alteração significativa no peso de ovos pelo efeito das diferentes relações de Ca:Pd. Da mesma forma, LIM et al. (2003) relataram que a relação 20:1 Ca:Pd (3\% Ca e 0,15\% Pd) e 300FTU kg-1 de dieta não afetou o peso de ovos de poedeiras, no período da $21^{\text {a }}$ a $30^{\underline{a}}$ semanas de idade.

Segundo JALAL \& SCHEIDELER (2001), que alimentaram poedeiras da $40^{\mathrm{a}}$ a $60^{\mathrm{a}}$ semanas de idade, com dietas à base de milho e farelo de soja, utilizando relações de Ca:Pd de 10,7:1; 15:1; 25:1 e 37,5:1, correspondendo a um nível de Ca de $3,75 \%$, e quatro níveis de Pd, sendo eles: 0,35\%, 0,25\%, 0,15\%, e 0,10\%; e com adição de fitase de 250 a $300 F T U ~ k g^{-1}$ de dieta, não encontraram diferenças significativas sobre o peso de ovos.

A unidade Haugh da mesma forma não foi afetada pelas relações $\mathrm{Ca}: \mathrm{Pd}$, fitase ou interações com a enzima em nenhum dos períodos avaliados. Porém, BORRMANN (2001) encontrou diminuição na unidade Haugh com o aumento das relações Ca:Pd.

A gravidade específica dos ovos não foi influenciada pelos tratamentos utilizados em nenhum dos períodos avaliados, contrariando GORDON \& ROLAND (1998), que observaram melhora linear na gravidade específica $(\mathrm{P}<0,001)$ com o aumento das relações Ca:Pd (25:1; 28:1; 31:1; 8,3:1; 9,3:1 e 10,3:1)e também com a interação das relações $\mathrm{Ca}: \mathrm{Pd}$ e fitase $300 \mathrm{FTU} \mathrm{kg}^{-1}$ de dieta.

$\mathrm{O}$ aumento das relações de $\mathrm{Ca}: \mathrm{Pd}$ causaram efeito significativo $(\mathrm{P}<0,05)$ sobre os teores de cálcio e matéria mineral nas tíbias (Tabela 3), elevando a percentagem desses minerais neste osso. Dessa forma, esses resultados concordam com estudos de GORDON \& ROLAND (1998), que, utilizando poedeiras de ovos marrons entre a $21^{\mathrm{a}}$ e a $32^{\mathrm{a}}$ semana de idade, obtiveram um aumento linear $(\mathrm{P}<0,001)$ da densidade óssea pelo

Tabela 3 - Efeito das diferentes relações cálcio:fósforo, fitase e interação (Ca:Pd x fitase) sobre o teor (\%) de fósforo, cálcio e matéria mineral das tíbias, das poedeiras UFSM-V.

\begin{tabular}{|c|c|c|c|}
\hline \multirow{2}{*}{ Relação cálcio:fósforo } & \multicolumn{3}{|c|}{ 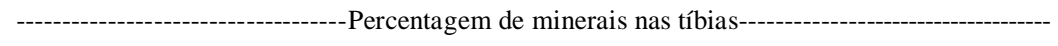 } \\
\hline & -------------Fósforo------------ & -------------Cálcio------------- & -------Matéria Mineral------- \\
\hline $8: 1$ & $8,49 \pm 0,10 \mathrm{ab}$ & $20,59 \pm 0,52 b$ & $43,53 \pm 0,70 \mathrm{~b}$ \\
\hline 11:1 & $8,24 \pm 0,06 \mathrm{~b}$ & $21,53 \pm 0,25 \mathrm{ab}$ & $45,56 \pm 0,52 \mathrm{ab}$ \\
\hline 14:1 & $8,61 \pm 0,09 \mathrm{a}$ & $22,24 \pm 0,20 \mathrm{a}$ & $46,53 \pm 0,81$ a \\
\hline \multicolumn{4}{|l|}{ Níveis de fitase } \\
\hline Sem enzima & $8,55 \pm 0,06$ & $20,61 \pm 0,36 \mathrm{~b}$ & $45,52 \pm 0,55$ \\
\hline Com enzima & $8,35 \pm 0,08$ & $22,29 \pm 0,12 \mathrm{a}$ & $45,90 \pm 0,65$ \\
\hline \multicolumn{4}{|l|}{ Interação Ca:Pd x fitase } \\
\hline 8: 1 com fitase & $8,28 \pm 0,13 \mathrm{ab}$ & $20,63 \pm 0,13 b$ & $44,75 \pm 0,13 \mathrm{ab}$ \\
\hline $8: 1$ sem fitase & $8,14 \pm 0,05 b$ & $18,89 \pm 0,12 \mathrm{c}$ & $42,32 \pm 0,52 b$ \\
\hline 11:1 com fitase & $8,33 \pm 0,09 a b$ & $22,29 \pm 0,13 \mathrm{a}$ & $45,07 \pm 0,61 \mathrm{ab}$ \\
\hline 11:1 sem fitase & $8,38 \pm 0,16 a b$ & $22,42 \pm 0,19 a$ & $46,04 \pm 0,85 \mathrm{ab}$ \\
\hline 14:1 com fitase & $8,71 \pm 0,14 \mathrm{a}$ & $22,31 \pm 0,28 \mathrm{a}$ & $46,16 \pm 0,95 \mathrm{ab}$ \\
\hline 14:1 sem fitase & $8,52 \pm 0,13 \mathrm{ab}$ & $22,17 \pm 0,30 \mathrm{a}$ & $46,90 \pm 1,38 \mathrm{a}$ \\
\hline \multicolumn{4}{|l|}{$\mathrm{P}$} \\
\hline Relação cálcio:fósforo & 0,0145 & 0,0109 & 0,0129 \\
\hline Níveis de fitase & 0,0716 & 0,0001 & 0,1175 \\
\hline Interação Ca:Pd x fitase & 0,0336 & 0,0001 & 0,0001 \\
\hline $\mathrm{CV} \%$ & 3,53 & 2,44 & 5,17 \\
\hline
\end{tabular}

Médias seguidas de letras diferem-se estatisticamente nas colunas pelo teste Tukey $(\mathrm{P}>0,05)$.

Ciência Rural, v.41, n.10, out, 2011. 
aumento da relação Ca:Pd (8,3:1; 10:1; 11,6:1;13,3:1; 15:1; e $16,6: 1)$, sendo $0,3 \%$ Pd e seis níveis de $\mathrm{Ca}(2,5 ; 3,0$; $3,5 ; 4,0 ; 4,5$ e $5,0 \%)$.

A fitase influenciou no teor de cálcio nas tíbias $(\mathrm{P}=0,001)$, assim como se pode observar aumento numérico do teor de cinzas pelo efeito da enzima, semelhante aos dados encontrados por GORDON \& ROLAND (1998), que obtiveram um aumento do teor de cinzas óssea de $6,01 \%$ e de $5,8 \%$ na densidade óssea pelo efeito da suplementação de fitase nas dietas (300FTU kg-1). Os valores encontrados para o percentual de cinzas na tíbia estão de acordo com os encontrados por SILVA et al. (2008), que variaram de $41 \%$ a $44 \%$ entre a $18^{\mathrm{a}}$ e $42^{\mathrm{a}}$ semana de idade de poedeiras de ovo de casca marrom. Nesse mesmo estudo, encontraram efeito quadrático dos níveis de fitase $\left(0 ; 300 ; 600 ; 1200 \mathrm{FTU} \mathrm{kg}^{-1}\right.$ de dieta) sobre o teor de cinzas das tíbias, com ponto de máxima deposição em 567FTU kg-1 de dieta.

A fitase $\mathrm{e}$ as diferentes relações cálcio:fósforo apresentaram efeito $(\mathrm{P}=0,0145)$ sobre a percentagem de fósforo nas tíbias das aves. O maior valor de fósforo nas tíbias foi encontrado quando as aves foram submetidas a dietas com relação Ca:Pd de 14:1, sendo que os percentuais de fósforo da tíbia estão de acordo com os encontrados por JARDIM FILHO et al. (2005).

\section{CONCLUSÃO}

Aves poedeiras de ovos marrons apresentam desempenho zootécnico similar quando alimentadas com diferentes relações $\mathrm{Ca}: \mathrm{Pd}$, independente da utilização ou não da enzima fitase na dieta. A qualidade óssea de aves de postura melhora significativamente pelo aumento das relações Ca:Pd. Dietas com relação Ca:Pd de 8:1apresentaram interação com a enzima melhorando o nível de $\mathrm{Ca}$ das tíbias das aves (Ca na tíbia=20,63\%). Com relação Ca:Pd igual ou superior a 11:1, não houve interação com a fitase, porém as aves apresentaram percentagem de Ca superior na tíbia $(\mathrm{Ca}$ na tíbia $\pm 22 \%$ ).

\section{REFERÊNCIAS}

BORGES, F.M.O. Utilização de enzimas em dietas avícolas. Caderno Técnico da Escola de Veterinária UFMG, Belo Horizonte, n.20, p.5-30, 1997.

BORRMANN, M.S. Efeitos da adição de fitase com diferentes níveis de fósforo disponível em dietas de poedeiras de segundo ciclo. Ciências Agrotécnicas, Lavras, v.25, n.1, p.181-187, 2001.
COSTA, F.G.P. et al. Níveis de fósforo disponível e de fitase na dieta de poedeiras de ovos de casca marrom. Ciência Animal Brasileira, Goiânia, v.5, n.2, p.73-81, 2004.

GORDON, R.W.; ROLAND, D.A. Influence of supplemental phytase on calcium and phosphorus utilization in laying hens. Poultry Science, Savoy, v.77, p.290-294, 1998. Disponível em: <http://ps.fass.org/cgi/reprint/77/2/290>. Acesso em: 25 jan. 2009 .

JALAL, M.A.; SCHEIDELER, S.E. Effect of supplementation of two different sources of phytase on egg production parameters in laying hens and nutrient digestiblity. Poultry Science, Savoy, v.80, p.1463-1471, 2001. Disponível em: <http:// ps.fass.org/cgi/reprint/80/10/1463>. Acesso em: 01 set. 2009.

JARDIM FILHO, R.M. et al. Influência das fontes e granulometria do calcário calcítico sobre o desempenho e a qualidade da casca dos ovos de poedeiras comerciais. Acta Scientiarum. Animal Sciences, Maringá, v.27, n.1, p.3541, 2005. Disponível em: <http://periodicos.uem.br/ojs/ index.php/ActaSciAnimSci/article/view/1239/675>. Acesso em: 23 set. 2009. doi: 10.4025/actascianimsci.v27i1.1238.

LIM, H.S. et al. Effects of phytase supplementation on the performance, egg quality, and phosphorous excretion of laying hens fed different levels of dietary calcium and nonphytate phosphorous. Poultry Science, Savoy, v.82, p.92-99, 2003. Disponível em: <http://ps.fass.org/cgi/reprint/82/1/92>. Acesso em: 18 ago. 2010.

LUCAS, A.M.; STETTENHEIM, P.R. Avian Anatomy: integument. I \& II. Washington, D.C.: USDA, 1972. (Agriculture Handbook 362).

LÜDKE, M.C.M.M. et al. Utilização da fitase em dieta com ou sem farelo de arroz desengordurado para suínos em crescimento/ terminação. Revista Brasileira de Zootecnia, Piracicaba, v.31, n.5, p.2002-2010, 2002. Disponível em: <http:// www.scielo.br/pdf/rbz/v31n5/a16v31n5.pdf>. Acesso em: 3 jun. 2009. doi: 10.1590/S1516-35982000000200023.

MALAVOLTA, E. et al. Avaliação do estado nutricional das plantas: princípios e aplicações. Piracicaba: POTAFOS, 1989. 219p

McKNIGHT, W.F. Phytase technical specifications and properties. Korea: Korean Society of Animal Nutrition and Feedstuffs, 1997. V.7. (Short Course on Feed Tecnology).

RAVINDRAN, V. et al. Phytates: occurrence, bioavailability and implications in poultry nutrition. Poultry \& Avian Biology Reviews, Northwood, v.6, p.125-143, 1995.

ROLAND, D.A.; GORDON, R. Metabolism and role of phosphorus, calcium and vitamin D3 in layer nutrition. Alabama: Album University, 1996. 11p.

ROSTAGNO, H.S. et al. Tabelas brasileiras para suínos e aves: composição de alimentos e exigências nutricionais. Viçosa: Universidade Federal de Viçosa, 2000. 141p.

STATISTICAL ANALYSES SYSTEM - SAS. User's guide: statistics. version. 6.12.ed. Cary, 1996. 983p.

SILVA, D.A. Análise de alimentos: métodos químicos e biológicos. Viçosa: Universidade Federal de Viçosa, 1981. 166p. 
SILVA, J.H.V. et. al. Influência da interação fósforo disponível $\times$ fitase da dieta sobre o desempenho, os níveis plasmáticos de fósforo e os parâmetros ósseos de poedeiras comerciais. Revista Brasileira de Zootecnia, Piracicaba, v.37, n.12, p.2157-2165, 2008. Disponível em: <http://www.scielo.br/pdf/ rbz/v37n12/12.pdf>. Acesso em: 16 jun. 2010. doi: 10.1590/ S 1516-35982008001200012.

TANGENDJAJA, B. et al. Effects of different sources of microbial phytase on production performance of brown-egg layers fed diets containing a high level of rice bran. Journal Applied Poultry Research, Savoy, v.11, n.2, p.212-216, 2002.

VIANA, T.S. et al. Efeito da suplementação de enzima fitase sobre o metabolismo de nutrientes e o desempenho de poedeiras. Revista Brasileira de Zootecnia, Piracicaba, v.38, n.6, p.1074-1080, 2009. Disponível em: <http://www.scielo.br/pdf/ rbz/v38n6/v38n6a15.pdf $>$. Acesso em: 20 maio, 2010. doi: 10.1590/S1516-35982009000600014. 